\title{
Modelling Browning and Brown Spotting of Mushrooms (Agaricus bisporus) Stored in Controlled Environmental Conditions Using Image Analysis
}

\author{
Catherine Barry-Ryan \\ Technological University Dublin, Catherine.Barryryan@tudublin.ie \\ Jesus Maria Frias \\ Technological University Dublin, Jesus.Frias@tudublin.ie \\ Leixuri Aguirre \\ Technological University Dublin, leixuri.aguirre@tudublin.ie
}

See next page for additional authors

Follow this and additional works at: https://arrow.tudublin.ie/schfsehart

Part of the Food Science Commons, and the Plant Sciences Commons

\section{Recommended Citation}

Aguirrea, L. et al. (2009) Modelling browning and brown spotting of mushrooms (Agaricus bisporus) stored in controlled environmental conditions using image analysis. Journal of Food Engineering, Vol. 91, (2) March 2009, pp. 280-286. doi:10.1016/j.jfoodeng.2008.09.004

This Article is brought to you for free and open access by the School of Food Science and Environmental Health at ARROW@TU Dublin. It has been accepted for inclusion in Articles by an authorized administrator of ARROW@TU Dublin. For more information, please contact arrow.admin@tudublin.ie, aisling.coyne@tudublin.ie, gerard.connolly@tudublin.ie.

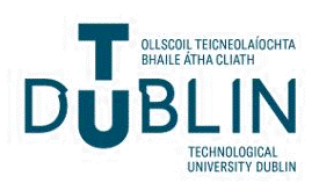


Authors

Catherine Barry-Ryan, Jesus Maria Frias, Leixuri Aguirre, and Helen Grogan

This article is available at ARROW@TU Dublin: https://arrow.tudublin.ie/schfsehart/18 


\title{
Journal of Food Engineering 91 (2009) 280-286
}

\section{Modelling browning and brown spotting of mushrooms (Agaricus bisporus) stored in controlled environmental conditions using image analysis}

\author{
L. Aguirre1, J. Frias1, Catherine Barry-Ryan1, H. Grogan 2
}

1. School of Food Science and Environmental Health, Dublin Institute of Technology, Cathal Brugha Street, Dublin 1, Ireland

2. Teagasc, Kinsealy R\&D Centre, Malahide Road, Dublin 17, Ireland

\begin{abstract}
A bstract
Mushrooms have a short postharvest shelf life compared to most vegetables, due to a very high metabolic activity and high water content, making them prone to microbial spoilage and to exhibit enzymatic browning.

Storage conditions and natural product variability are both important factors that affect the management of mushrooms, and both of them can be managed using monitoring systems. In order to study the effect of the temperature and relative humidity on the whiteness decrease and appearance of brown spotting, an image analysis system was employed. Twenty five batches of mushrooms were subjected to combinations of three storage temperatures $(\mathrm{T})\left(5^{\circ} \mathrm{C}, 15^{\circ} \mathrm{C}\right.$ and $\left.25^{\circ} \mathrm{C}\right)$ and three storage relative humidity $(\mathrm{RH})(70 \%, 80 \%$ and $90 \%)$. Further validation experiments were performed at lower and higher temperatures.

The study showed that the kinetics of colour degradation and spotting followed a logistic pattern, and that best storage conditions to delay the onset of browning and spotting could be found at high relative humidities $(<90 \%)$ and refrigeration temperatures as high as $11^{\circ} \mathrm{C}$ without a significant reduction of the whiteness or development of browning during the first two days compared to mushrooms stored at $3^{\circ} \mathrm{C}$ Mushrooms stored at $1{ }^{\circ} \mathrm{C}$ for longer than two days, would have quick drop in colour. This findings are in agreement with current practise in retail, where mushrooms normally arrive from the agricultural producer at very low storage temperatures $\left(0-3^{\circ} \mathrm{C}\right)$ and is then retailed at vegetable display conditions $\left(8-11^{\circ} \mathrm{C}\right)$ with a very quick product replacement rate.
\end{abstract}

Keywords:

Image analysis, Mushroom, Storage, Kinetics, Modelling, Non-linear mixed effect

1. Introduction

Mushrooms have a short postharvest shelf life of 3-4 days compared to most vegetables, mainly because they have no cuticle to protect them from physical or microbial attack and water loss. The cultivated mushroom (Agaricus bisporus) is highly susceptible to blemishes caused by a range of bacterial and fungal pathogens, and discolouration induced by bruising, storage and physiological disorders (Vízhányó and Felföldi, 2000). In the same way, they have a very high respiration rate and high water content, making them prone to microbial spoilage. Finally their high tyrosinase and phenolic content makes them very susceptible to enzymatic browning (Brennan et al., 2000)

The main processes which contribute to loss in quality after harvest are (i) discolouration, (ii) browning, (iii) loss of closeness, (iv) weight loss and (v) texture changes (Burton and Noble,

1993; Berendse, 1984). The colour and the shape of the cap is the most important consideration of fresh mushrooms, since it is the first characteristic consumers notice (Brosnan and Sun, 2004).

After harvest the mushroom colour gradually changes from white to brown, due to the appearance of browning and possibly bacterial blotching, while the growth of the stipe and the cap continues. The cap growth results in gradual opening of the mushroom cap (Lukkasse and Polderdijk, 2003).

Despite the efforts of agricultural production, classification and packaging, one of the main problems in mushroom production is the uncontrollable effect of the natural product variability. From a retailer point of view different batches of mushrooms arrive at a different maturity stage and inside every batch there is natural product heterogeneity. This variability results in important losses from the retailer-producer point of view and monitoring systems can help to study and manage this natural variability.

Colour can be rapidly analyzed by computerized image analysis techniques. These systems not only offer a methodology for measurement of uneven colouration but can also be applied to the measurement of other attributes of the total appearance (Hutchings, 1999). Computer analysis of camera images of mushroom caps may offer several advantages over visual assessment. It may be 
possible to discriminate types of blemish mathematically from the spectral characteristics. Information about blemishes with known causes can be stored and compared with new images. The equip ment could be operated by a non-specialist, and give an immediate objective result (Vízhányó and Felföldi, 2000).

The agricultural industry uses measurements of colour mainly due to three reasons: (i) colour serves as instant indicator of product quality, (ii) colour measurement has been employed to develop optimal storage policies with the aim to maintain appealing

appearance through (white and uniform colour) the shelf life and

(iii) the most important use of colour is to provide a buying criterion in the purchase of products (Abdullah et al., 2004).

The aim of this work is to find the best storage conditions in terms of relative humidity and temperature that maintain the visual quality of mushroom. In order to do so a study of: (i) the average colour kinetics of mushroom caps during storage, (ii) the appearance of brown spotting in mushrooms during storage and (iii) an assessment of the effect that variability in a retail situation has on the management of this products using a continuous image analysis system was performed.

\section{Materials and methods}

\subsection{Experimental design}

Closed cup mushrooms A. bisporus Sylvan A15 (white, close, uniform, clear, and fresh) with density of $0.547 \pm 0.005 \mathrm{~g} / \mathrm{cm}_{3}$, water content of $14.8 \pm 0.6 \mathrm{~g}$ water/g dry, $\mathrm{L}^{*}$ of $83 \pm 7 \mathrm{a}^{*}$ value of $1.4 \pm 1, b^{\star}$ value of $13 \pm 2$, weight of $24 \pm 7 \mathrm{~g}$ were purchased from a local supermarket (Dunnes Stores, Dublin, Ireland) on produce arrival day. It is expected that this would be one day after harvest, representing a typical medium size retail situation. The experiments were carried out over $1 \frac{1}{1} 2$ years (April 2004-October 2005).

Accelerated experiments, in order to study the senescence, were performed in an environmental incubator (MLR-350 HT, SANYO Electric Biomedical Co. Ltd., Japan) with temperature, relative humidity and lighting conditions controlled. The study involved monitoring of the mushrooms at three temperatures $(\mathrm{T})$ levels $\left(5^{\circ} \mathrm{C}, 15^{\circ} \mathrm{C}\right.$ and $\left.25^{\circ} \mathrm{C}\right)$ and three relative humidity $(\mathrm{RH})$ levels $(70 \%, 80 \%$ and $90 \%)$ in a 32 full factorial design for up to 10 days, based on conditions researched in previous studies (Escriche et al., 2001; Pai, 2000). Each combination was carried out a minimum of two times using six mushrooms in each experiment. Two further experiments were performed at lower temperature $\left(3^{\circ} \mathrm{C} \& 70 \% \mathrm{RH}\right.$ and $3{ }^{\circ} \mathrm{C} \& 80 \% \mathrm{RH}$ ) and one at a higher temperature $\left(30{ }^{\circ} \mathrm{C} \& 80 \% \mathrm{RH}\right)$ to investigate if there were possible departures from the model assumptions at lower or higher temperature ranges that could affect mushroom storage. A total of 25 experiments amounting to 128 individual mushroom kinetics and 3864 experimental measures were taken.

\subsection{Image acquisition}

The mushroom batches were monitored using inexpensive webcams under controlled illumination conditions (LogitechÒ QuickCamÒ Express, Logitech Europe S.A, DE). The images were taken every hour inside an incubator with controlled illumination conditions. A light source of a fluorescent lamp (40 W) was incorporated into the incubator. Six mushrooms were placed at the centre of the incubator tray covered in non-reflecting black cardboard and placed on a sample support painted in non-reflecting colour (black matte). At a sufficient distance not to interfere with the mushroom image, six non-reflecting coloured cardboard samples were placed. These cardboard samples were measured at the beginning, the end of the experiment and between experiments with a colorimeter and used to control possible bias between experiments and drifts in the performance of the camera. These colour cardboard samples change were not significant during the experiments.

Camera and mushroom location were fixed in all the experiments. An automated protocol to (i) fix the camera settings and

(ii) automate camera image acquisition was developed using Java (Sun Microsystems Inc., Santa Clara, CA, USA).

\subsection{Image analysis}

Image analysis was performed using Image $\mathrm{J}(\mathrm{NIMH}$, National Institute of Mental Health, Bethesda, Maryland, USA). The image was transformed from the RGB space to an 8-bit greyscale image using the transformation.

Grey value $=\frac{\text { Red }+ \text { Green }+ \text { Blue }}{3}$

A region of interest (ROI) was selected in a stack of images comprising a whole mushroom cap over the storage time.

There are two main colour attributes of mushroom which consumers use to accept or reject the product, the appearance of brown spots and the general browning of the cap follows in order of importance. The following image indexes were extracted:

(1) The average greyscale value (grey value) kinetics of the ROI were employed as a measurement of the whiteness $\left(L^{*}\right)$ and general browning of the mushroom. Under these controlled illumination situation and range of greyscale for the camera, a linear relationship between the $L^{*}$ and the greyscale was found.

(2) The standard deviation (SD) of the ROI was used as a contrast measurement to follow the appearance of brown spotting.

In the case of the local standard deviation the kinetic was associated to the onset of brown spotting in the cap of the mushrooms. The kinetics of this quality index showed the transition from white to spotted cap.

\subsection{Mathematical modelling}

Both average grey value and standard deviation kinetics could be accommodated with a typical sigmoideal shape (Fig. 1) with a transition from "fresh mushroom" to "brown mushroom" and were modelled using a logistic model (Pinheiro and Bates, 2000):

$$
\text { Grey }- \text { Grey }_{\text {Initial }} \sim \frac{\text { Drop }}{1+e^{\frac{\text { tamer-time }_{\text {Gere }}}{G}}}
$$

where Grey is the particular response under observation, Drop is the change from the initial (white) state to the final (brown) state, trans is the transition time needed to get the middle point of the transition, tcrit stands for the critical time defining the speed of the transition.

\subsection{Variability modelling}

Two nested random effects (batch to batch and sample to sample inside a batch) were assigned to each parameter (Drop, trans and tcrit) to construct a nonlinear mixed effect model.

\subsection{Secondary modelling}

The main secondary variables affecting the storage kinetics of the mushroom were the temperature and the relative humidity. The Vapour Pressure Deficit (VPD) was used instead of the $\mathrm{RH}$ in order to avoid the interaction between $\mathrm{T}$ and $\mathrm{RH}$ (Aguirre et al., 

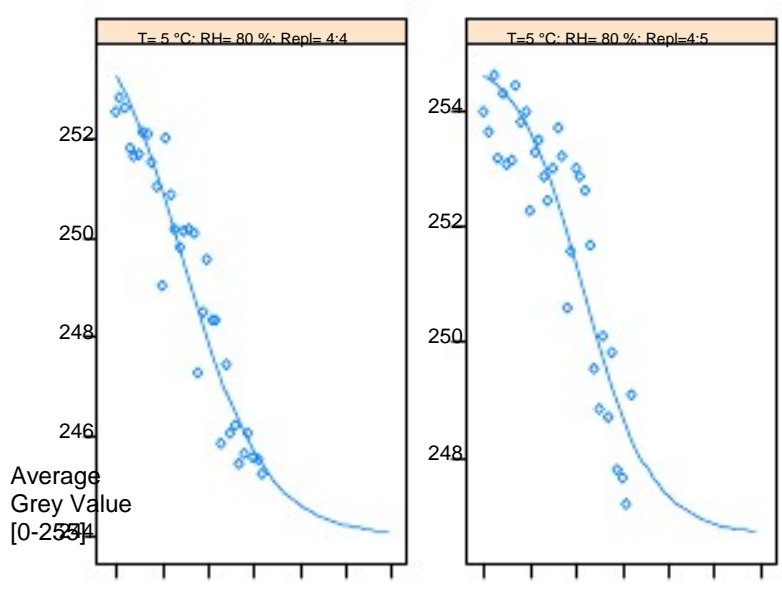

$0 \quad 50100150200250300$

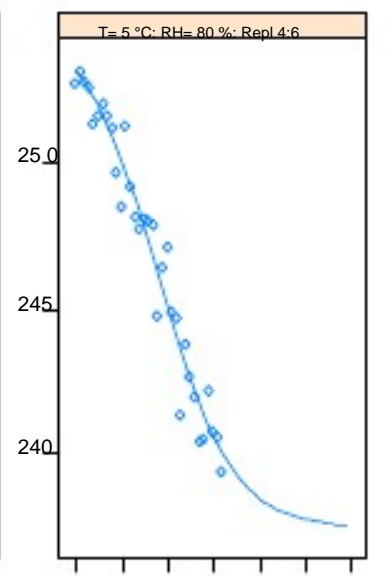

$0 \quad 50100150200250300$

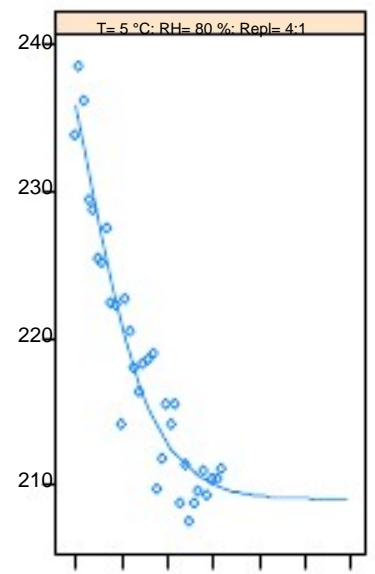

050100150200250300

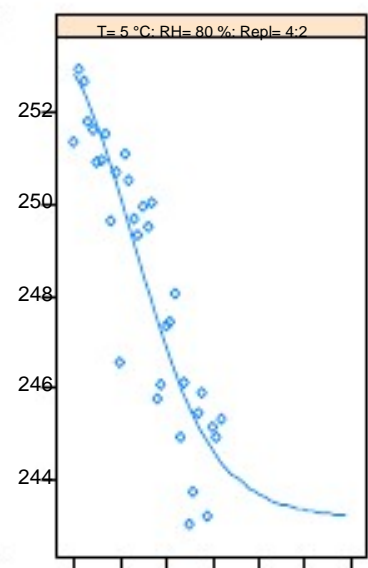

050100150200250300

Storage time $[\mathrm{h}]$

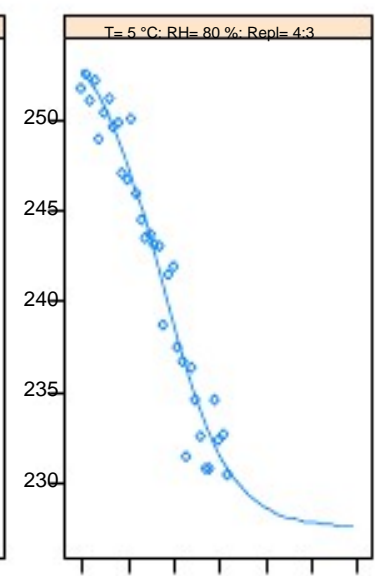

050100150200250300

Fig. 1. The best linear unbiased predictions (BLUP) of the grey value kinetics of 6 typical mushrooms at different environmental conditions. The legend in the strip on top of each panel describes the storage conditions (i.e. $\mathrm{T}=15^{\circ} \mathrm{C}: \mathrm{RH}=80 \%$ : rep $=4: 6$ means that the temperature of the experiment was $15^{\circ} \mathrm{C}$, the relative humidity was $80 \%$, it was the experiment number 4 and mushroom 6 ).

2008). The VPD is the difference between the amount of moisture in the air and how much moisture the air can hold when it is saturated. VPD functions as a convenient indicator of the condensation potential. VPD is possible to calculate using the following equation (Perry and Green, 1997):

$$
\mathrm{VPD}=\mathrm{VP}_{\mathrm{sat}}-\mathrm{VP}_{\text {air }}
$$

where VPD is the vapour pressure deficit $(\mathrm{kPa}), \mathrm{VP}$ sat $(\mathrm{kPa})$ is the saturation vapour pressure which is directly related to temperature and VPair $(\mathrm{kPa})$ is the water vapour in the air, which is how much water in the gas form is present in air. They were calculated as follows (Aguirre et al., 2008):

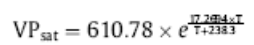

$\mathrm{VP}_{\text {air }}=\frac{\mathrm{RH}}{100} \times \mathrm{VP}_{\text {sat }}$

The secondary model was built by adding polynomial model terms with storage conditions (fixed effects) of temperature $(T)$ and vapour pressure deficit (VPD) and product variability (random effects) to the primary model parameters and then tested for model improvements using a log-likelihood ratio test in a stepwise fashion. The final model components were as follows.

The model building process followed a series of steps:

(1) An initial model was built with random effect terms and no dependence of the parameters with T or VPD.
(2) A summary of the model was produced with t-statistics for each individual model coefficient and Wald tests for each model term.

(3) Based on the Wald test statistics of significance for the fixed effect non-significant terms of the model were eliminated (Pinheiro and Bates, 2000)

(4) Polynomial model terms with storage conditions ( $T$ and VPD) were added.

(5) A summary of the new model was produced with Wald tests for each model term.

(6) The logarithm likelihood ratio test and the Akaike Information Criteria were employed to compare the new model with the previous one.

(7) Steps 2-6 were repeated until a satisfactory model augmentation was achieved.

Finally, in order to assess the suitability of the best model, the random effects and residuals were studied for seasonality effects.

\section{Results and discussion}

3.1. Results and discussion of the grey value

The whiteness kinetic of the mushroom decreased with time, and brown spotting kinetic showed an increase with time. Both kinetics were influenced by environmental conditions of $\mathrm{T}$ and $\mathrm{RH}$ (Fig. 1). 
Although variability played an important role, the environmental conditions also exerted an effect on the colour kinetics, with some storage conditions slowing colour degradation kinetics.

After the model building work outlined a final candidate model was selected. Table 1 shows the estimated different parameters fo the grey value kinetics. The asymptotic estimate of the grey value decrease depended on the temperature $(T)$. The time required to reach half of the browning transition point (trans parameter) was significantly affected by the temperature, vapour pressure deficit, quadratic effect of the temperature and the interaction between the temperature and the vapour pressure deficit. The speed at which the browning transition process took place, expressed by tcrit parameter, was only affected by temperature. The quadratic effects on the transition time (trans) pointed to possible optimal storage conditions that may decrease the kinetics of the browning process and extend the time necessary to arrive to the middle point of the transition from white to brown.

Fig. 1 shows a selection of experimental data set with best linear unbiased predictions (BLUP) of the model. The BLUP may be used to compare the behaviour of the grey value for existing mushroom batches within the same environmental conditions. It was possible to see how the model accommodated the data and described appropriately their kinetics.

The residual plot showed the residuals were randomly distributed. There were some outliers, which is a typical situation in modelling of continuous monitoring devices, where the magnitude of the data available (3864 experimental data) and possible instrumental deviations impairs the modelling process.

Table 1

Estimated parameters from the non-linear logistic mixed effect model

\begin{tabular}{|c|c|}
\hline Parameter & Estimate \\
\hline $\begin{array}{l}\text { Drop [0-255] } \\
\text { Transition Time [h] }\end{array}$ & $\begin{array}{l}\text { À6.7(7.7)-1.55(0.49)*T } \\
79.1(15.6)+5.5(2.6)^{*} \mathrm{~T}-220(102.4) * \mathrm{VPD} \\
\text { À0.32(0.13) }{ }^{*} \mathrm{~T} 2+10.72(4.8)^{*} \mathrm{~T} \text { *VPD } \\
38.9(3.1)-0.66(0.2) * T\end{array}$ \\
\hline \multicolumn{2}{|l|}{ Critical Time [h] } \\
\hline \multicolumn{2}{|c|}{ Variability between samples } \\
\hline rorop [0-255] & $48.8(39-62)$ \\
\hline Transition time [h] & $42.8(37-50)$ \\
\hline rCritical time [h] & $15.1(12-18)$ \\
\hline \multicolumn{2}{|l|}{ Error term } \\
\hline$r$ [0-255] & $2.14(2.09-2.19)$ \\
\hline
\end{tabular}

The standard error of each coefficient is presented in subscripted brackets. All

effects were significant $(p<0.05)$
From Table 1 it was possible to generate a map of the dependence of the model parameters with storage conditions. Fig. 2 indicates how the transition time from "white" to "brown" changed with the temperature, the VPD and the $\mathrm{RH}$. It can be seen in Fig. $2 a$ that the best way to delay the browning of the mushroom would be to employ a low storage temperature $\left(\$ 5^{\circ} \mathrm{C}-15^{\circ} \mathrm{C}\right)$ and low water vapour pressure deficit $(\$ 0.2)$ where the mushroom would maintain its water content and the grey value would not start this transition decrease for at least 3.5 days. In the case of higher temperature, the water vapour pressure deficit also increased, therefore drying the mushroom. At these conditions the whiteness is maintained but the quality of the product is not acceptable. Although VPD is a conventional variable for refrigeration technology, package designers and food technologist usually employ the $\mathrm{RH}$. Fig. $2 \mathrm{~b}$ indicates that the best conditions to delay the onset of brown colour on the mushroom cap were low temperatures $\left(\$ 4^{\circ} \mathrm{C}-13^{\circ} \mathrm{C}\right)$ and high $\mathrm{RH}$ (close to saturation). Under these conditions, the whiteness was maintained for a similar time. The Fig. $2 \mathrm{~b}$ also shows that in storage conditions where the relative humidity was higher than $80 \%$ and temperature was between $0{ }^{\circ} \mathrm{C}$ and $18^{\circ} \mathrm{C}$ the whiteness is maintained for three days.

In Fig. $2 \mathrm{~b}$ at $25^{\circ} \mathrm{C}$ and relative humidity below $40 \%$ the whiteness was maintained for 10 days. In this case, due to the high temperature the mushroom lost so much water that it was dried and the colour did not have time to change.

Burton and Noble (1993), Pai (2000) and Pardo et al. (2001) proved that the decrease in whiteness was affected by the temperature and reported that lower temperatures decreased this whiteness loss, which was confirmed by the present finding. Lukkasse and Polderdijk (2003) reported that the temperature affected the shelf life of the mushrooms, being shorter when the temperature was increased. Furthermore, the present study showed that the relative humidity also affected the transition process from "white" to "brown". Fig. 2 shows that the relative humidity was an important factor and the maintenance of a high relative humidity during storage was necessary to maintain the whiteness of the mushrooms. It is possible to allow higher storage temperatures if the relative humidity is higher than $90 \%$. These results for the grey value decrease are in accordance with the previous results for the $L^{*}$ value obtained by Aguirre et al. (2008). The improvement in whiteness from storage at $25^{\circ} \mathrm{C}$ to $3^{\circ} \mathrm{C}$ is a $75 \%$ less browning (as seen by the relative change in the Drop parameter)
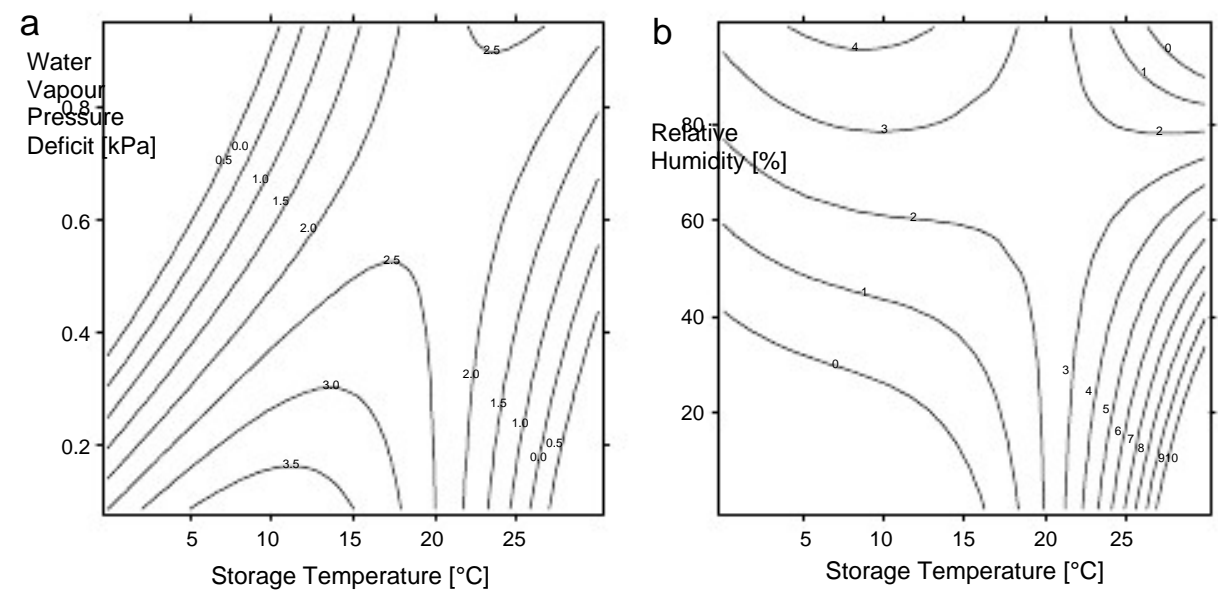

Fig. 2. (a) Contour plots of the dependence of the transition time of the grey value damage process on the water vapour pressure deficit (VPD) and/or (b) RH with the temperature of mushroom batches. 
Using the random effects sources of variability (and excluding the uncertainty from the estimated parameters, arising from the instrumental error of the acquisition system) stochastic simulations of different storage scenarios were performed in order to compare the average colour evolution of batches of mushrooms between (i) abused storage $\left(25^{\circ} \mathrm{C}\right.$ and $\left.90 \% \mathrm{RH}\right)$, (ii) retail guideline storage (Pai, 2000 and Pardo et al., 2001) conditions $\left(5^{\circ} \mathrm{C}\right.$ and $90 \% \mathrm{RH}$ ) and (iii) a proposed optimal arising from this study $\left(11^{\circ} \mathrm{C}\right.$ and $\left.95 \% \mathrm{RH}\right)$. A Monte Carlo simulation $(\mathrm{n}=15,000)$ was performed to obtain the $5 \%$ and $95 \%$ percentiles of the population of stored batches of mushrooms at each one of 50 equally spaced time points between the initial day and the 7th day of storage.

Storage of mushrooms in an abused situation produced a decrease of the grey value of an important part of the population of mushroom batches, with losses in the grey value becoming very important as storage sets on and for the first days

(Fig. 3a). As mushrooms decayed and entered the later phases of senescence, the differences in the grey value population decreases.

Fig. $3 \mathrm{~b}$ shows that taking into account the variability between batches of the system there was a marginal difference between the retail guidelines and a higher storage temperature optimal arising from this study. The effect between batches variability was very important in the fate of a mushroom during storage and the effect of decreasing temperature might not yield an effect of maintaining the whiteness of the mushrooms for all the energy that has been spent compared to storage at $11^{\circ} \mathrm{C}$. This storage of mushrooms at higher temperature occurs in the retail sector, at the point of receipt of the product and the following display of the product in the vegetable cabinets. Using this storage temperature mushrooms would keep, taking into account for variability, in a similar quality standard as mushrooms stored at much lower temperatures for at least two days, which is the turnover time of a fresh product. However, after the consumer bought this product, the toll of the high temperatures employed during retail would decrease the time during which mushrooms would keep at high quality in the consumers refrigeration unit. In order to pass to the consumer the maximum shelf life time of the product, the lower refrigeration temperatures should be employed, not only for post-harvest and distribution, but also for retail.
The SD, a measurement of the image contrast, may be employed to follow the development of browning spots in the mushroom cap. The kinetics of the local SD of the grey value of a whole mushroom cap region of interest $(\mathrm{ROI})$ was monitored for this purpose.

The secondary model was built by adding linear model terms with storage conditions (fixed effects) and product variability (random effects) to the primary model parameters and then testing for model improvements using a log-likelihood ratio test in a stepwise fashion. The final model components were as follows.

(1) Estimated fixed effects: (i) a linear effect with temperature was found for the Drop, (ii) a constant trans parameter and (iii) a quadratic dependence with temperature for the tcrit.

(2) Estimated Random effects: Independently distributed random effects associated to each of the mushrooms measured were assigned to the Drop, trans and tcrit to include the mushroom-to-mushroom variability in the shape of normal distributions and to Drop, trans to describe the batch-tobatch variability.

Table 2 shows that brown spotting was affected by the temperature but not by the relative humidity. The asymptotic of the grey value decrease depended on the temperature $(T)$. In the case of the speed at which browning took place (the tcrit parameter), the parameters that affected were the temperature and the quadratic effect of the temperature. Due to the presence of the quadratic ef-

Table 2

Estimated parameters from the non-linear logistic mixed effect model

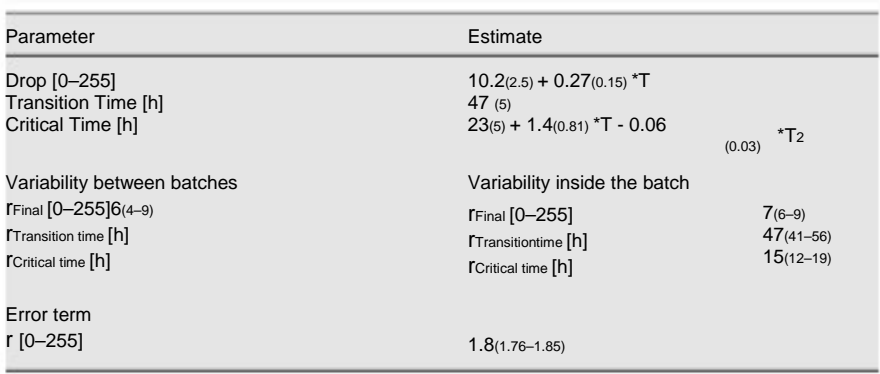

The standard error of each coefficient is presented in subscripted brackets. All effects were significant $(p<0.05)$


Fig. 3. Monte Carlo Assessment of the effect of variability in the potential improvement of storage conditions for the grey value kinetics. The polygons show the simulated $95 \%$ tolerance bands of mushrooms kinetics stored under different conditions. (a) Comparison of abuse storage (grey polygon, $25^{\circ} \mathrm{C}$ and $90 \% \mathrm{RH}$ ) and optimal storage $11^{\circ} \mathrm{C}$ and $95 \% \mathrm{RH}$ ). 
fect of the temperature it was possible to calculate an optimal storage temperature $\left(11^{\circ} \mathrm{C}\right)$ to slow down the brown spotting which is indicated in Fig. 6

Fig. 4 showed a selected example data set compared to the best linear unbiased predictions (BLUP) of the model. It can be seen how the model accommodated the experimental data.

The residual of SD were randomly distributed. The effect of the variability between mushrooms in the model parameters was assessed, affecting the final SD value (\$62\%), the transition time
$(\$ 50 \%)$ and finally the critical time (\$28\%). The uncertainty of the estimated parameters was lower than the random effects, except for the final SD value.

3.4. Scenario analysis and between batches variability assessment

Stochastic simulations of different storage scenarios were performed in order to compare the average brown spotting process in different batches of mushrooms between (i) abused storage
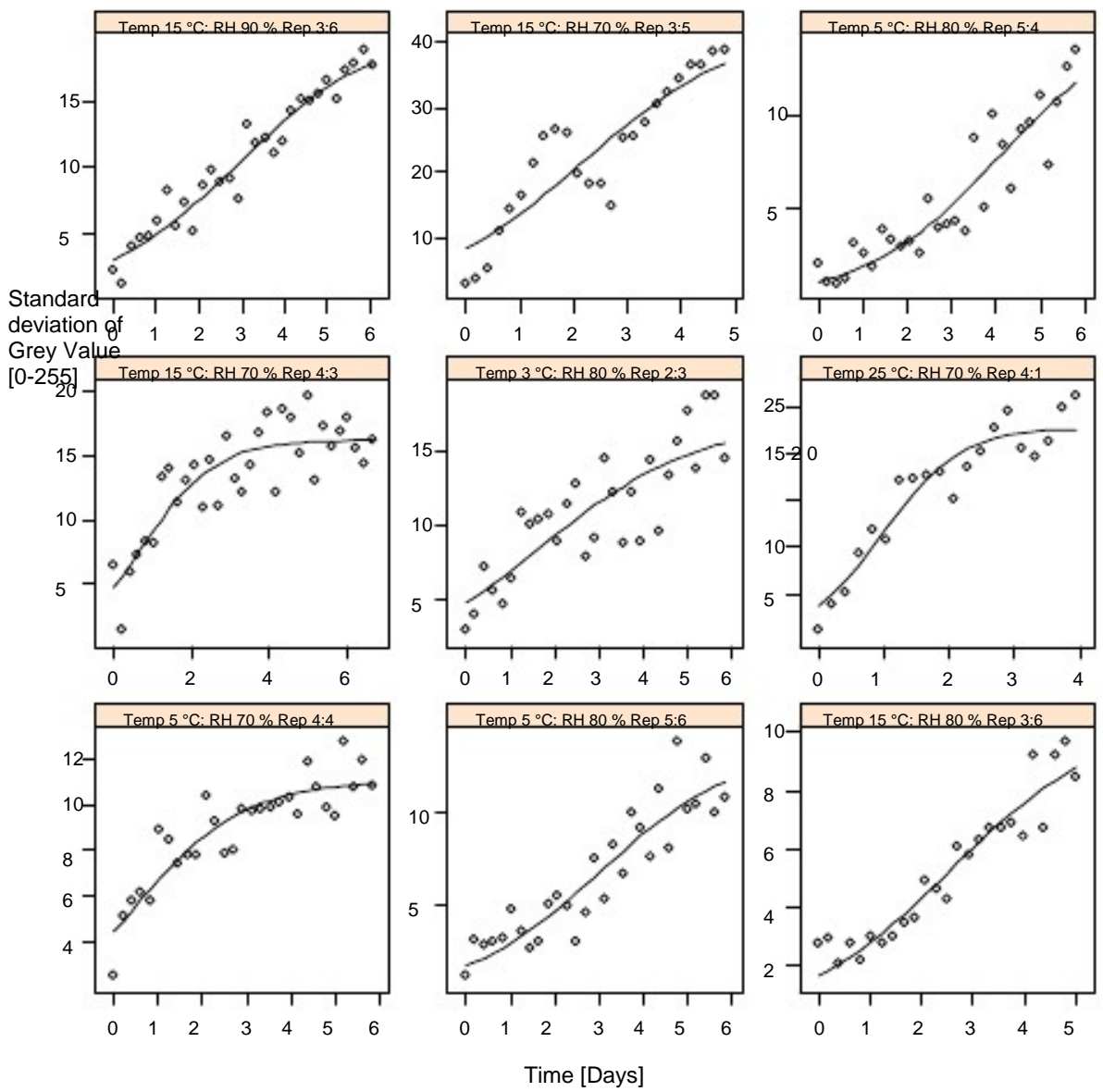

Fig. 4. The best linear unbiased predictions (BLUP) for the SD kinetics of 6 typical mushrooms at different environmental conditions. The legend in the strip on top of each
panel describes the storage conditions and the experiment and sample number (i.e. Temp $15{ }^{\circ} \mathrm{C}$ : RH $90 \%$ Rep $3 / 6$ describe the experiment conditions of storage at $15{ }^{\circ} \mathrm{C}$ and panel describes the storage conditions and the exper
$90 \% \mathrm{RH}$ experiment number 3 , sample number 6 ).


Fig. 5. Monte Carlo Assessment of the effect of variability in the potential improvement of storage conditions for the browning indicator (local standard deviation) value kinetics. The polygons show the simulated $95 \%$ tolerance bands of mushrooms kinetics stored under different conditions. (a) Comparison of abuse storage (grey polygon, $25^{\circ} \mathrm{C}$ ) and optimal storage (transparent polygon, $11^{\circ} \mathrm{C}$ ). (b) Comparison of guideline mushroom storage (grey polygon, $2^{\circ} \mathrm{C}$ ) and present study optimal (transparent polygon, $\left.11^{\circ} \mathrm{C}\right)$ 


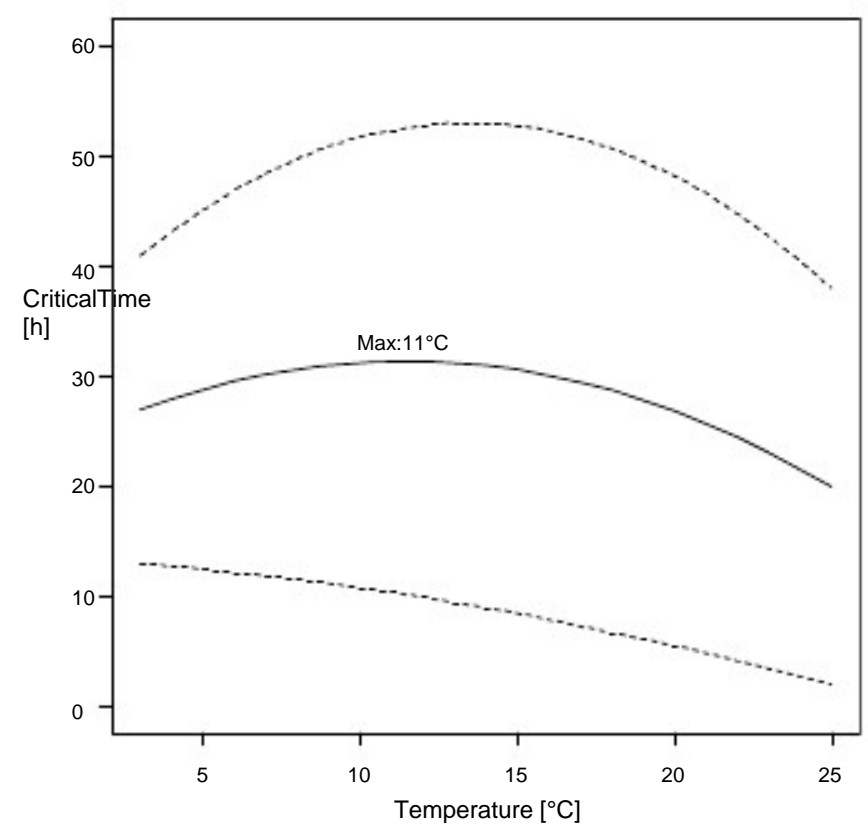

Fig. 6. The dependence of the SD critical time with temperature with a maximum at $11{ }^{\circ} \mathrm{C}$. The discontinuous lines represent the $95 \% \mathrm{Cl}$ taking into account the variability between batches.

(25 ${ }^{\circ} \mathrm{C}$ and $90 \% \mathrm{RH}$ ) (ii) retail guideline storage conditions $\left(5^{\circ} \mathrm{C}\right.$ and $90 \% \mathrm{RH}$ ) and (iii) a proposed optimal arising from this study $\left(11^{\circ} \mathrm{C}\right.$ and $\left.95 \% \mathrm{RH}\right)$. A Monte Carlo simulation $(n=15,000)$ was performed to obtain the $5 \%$ and $95 \%$ percentiles of the population of stored batches of mushrooms at each one of 50 equally spaced time points between the initial day and the 7th day of storage.

As it can be seen in Fig. $5 \mathrm{a}$, storage of mushrooms in an abused situation produced an increase of the brow spotting from the beginning of the storage which was constant in the entire storage time.

Fig. $5 \mathrm{~b}$ shows that taking into account the variability between batches of the system there was not difference between the guideline conditions and the proposed temperature in the development of the brown spotting during postharvest and the temperature could be increased by as much as $6^{\circ} \mathrm{C}$ therefore producing a big energy save. room. In the case of the grey value, the study showed that to maintain the grey value for as long as possible, four days, it was necessary to have low temperatures $\left(4^{\circ} \mathrm{C}-13^{\circ} \mathrm{C}\right)$ and high $\mathrm{RH}$ (close to saturation). The study showed that to maintain the grey value for three days, such extreme conditions are not necessary. If the temperature was between $0{ }^{\circ} \mathrm{C}$ and $18^{\circ} \mathrm{C}$ and the relative humidity higher than $80 \%$ the grey value was maintained for three days. These conditions can be more achievable because they were the conditions that the mushrooms are stored at the supermarket. However, if the retailer wished to pass the six days of shelf life to the consumer, lower storage temperatures at high relative humidity should be required during retail.

In the case of the standard deviation, the study proved that the appearance of the brown spotting was only affected by the temperature.

References

Abdullah, M.Z., Guan, L.C., Lim, K.C., Karim, A.A., 2004. The applications of compute vision system and tomographic radar imaging for assessing physical properties .

Aguirre, L. Frías, J.M. Barry-Ryan, C., Grogan, H. 2008. Assessing the effect of product variability on the management of the quality of mushrooms (Agaricus bisporus). Postharvest Biology and Technology 49, 247-254

Berendse, $H$., 1984. Attitudes to mushrooms revealed in bureau survey. Supplement to the Fruit Trades Journal. November 9 .

Brennan, M., Le Port, G., Gormley, R., 2000. Postharvest treatment with citric acid or hydrogen peroxide to extend the shelf life of fresh sliced mushrooms. Lebensmittel-Wissenschaft und-Technologie 33, 285-289.

Brosnan, T., Sun, D.-W., 2004. Inspection and grading of agricultural and food products by computer vision systems - a review. Journal of Food Engineering $61,3-14$

Burton, K.S., Noble, R., 1993. The influence of flush number, bruising and storage temperature on mushrooms quality. Postharvest Biology and Technology 3, 39-

Escriche, I., Serra, J.A., Gomez, M., Galotto, M.J., 2001. Effect of ozone treatment and storage temperature on physiochemical properties of mushrooms (Agaricus bisporus). Food Science and Technology International 7 (3), 251-258.

Hutchings, J.B., 1999. Food Colour and Appearance, vol. 593. Aspen publishers, Inc., Gainthersburg, MD

Lukkasse, L.J.S., Polderdijk, J.J., 2003. Predictive modelling of postharvest quality evolution in perishables, applied to mushrooms. Journal of Food Engineering 59, 91-198.

Pai, T., 2000. Effects of storage environmental conditions on weight loss whiteness change and microbial activity of mushrooms (Agaricus bisporus). Agricultura C. A Juan, J A. Pardo, J. 2001. Fisiol.

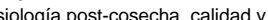
conservación del champiñón cultivado Agaricus bisporus (Lange) imbach. Acta 322 107-117.

Perry, R.H., Green, D.W., 1997. Perry's Chemical Engineers' Handbook, eighth ed. McGraw-Hill.

Pinheiro, J.C., Bates, D.M., 2000. Mixed-Effect Models in S and S-PLUS. Springer Verlag, New York, USA.

Vízhányó, T., Felföldi, J., 2000. Enhancing colour differences in images of diseased mushrooms. Computers and Electronics in Agriculture 26, 187-198.

\section{Conclusions}

The study showed that temperature and relative humidity are significant parameters that affected the whiteness of the mush- 